\title{
Colorectal Cancer: Epidemiological Study, Clinical, Histological and Immunohistochemistry Examination in Patient of West Algeria
}

\author{
F. Z. Bensaada*, H. Ould Cadi, T. Sahraoui, F. Z. El Kebir \\ Laboratory of Biology of Development and Differanciation, Department of Biology, Faculty of Natural Science and Life, University of \\ Oran 1 (Ahmed Benbella), Oran, Algeria \\ Email: *fatimazbenbou@gmail.com
}

How to cite this paper: Bensaada, F.Z., Cadi, H.O., Sahraoui, T. and El Kebir, F.Z. (2017) Colorectal Cancer: Epidemiological Study, Clinical, Histological and Immunohistochemistry Examination in Patient of West Algeria. Journal of Cancer Therapy, 8 , 26-36.

http://dx.doi.org/10.4236/jct.2017.81003

Received: November 10, 2016

Accepted: January 13, 2017

Published: January 16, 2017

Copyright (c) 2017 by authors and Scientific Research Publishing Inc. This work is licensed under the Creative Commons Attribution International License (CC BY 4.0).

http://creativecommons.org/licenses/by/4.0/

\begin{abstract}
Colorectal cancer (CRC) is significant publichealth problem in rich countries of the world, because of its frequency and mostly because of its severity. Our aim was to improve histologic diagnosis of malignancy with topographic coloration (HE) and cytokeratins 7, 20 immuno-labeling. The risk for colorectal cancer incease with age, but in our series, $10 \%$ of colorectal cancer exist in patients younger than 40 years old. In histological study, adenocarcinoma represented $100 \%$ and the evaluation for stage of disease showed that the most dominant isstage IV (32.6\%). In our trial, we found that cytokeratins 7 and 20 immunoreactivity in colorectal adenocarcinoma are often positive for cytokeratin-20 and most of time negative for cytokeratin-7.
\end{abstract}

\section{Keywords}

Adenocarcinoma, Colorectal Cancer (CRC), Cytokeratin (7, 20)

\section{Introduction}

Worldwide, the number of new cases of colorectal cancer was estimated at 1.4 million in 2012. This shows a relative increase in the incidence of these cancers. For this period by its frequency,CRC arranged third in men with 746,000 new cases and second in women with 614,000 new cases [1].

In Algeria, the incidence of colorectal cancer (3380 cases/year, or $8.9 \%$ ) is in second place after breast cancer ( 8177 cases/year $21.6 \%$ ). It is the second cancer in humans (1690 cases or 10.3\%) after lung cancer [2].

Five-year survival rate in colorectal cancer is about $60 \%-95 \%$ in the initial stages and decreases dramatically to $35 \%$ in stages where lymph node metastases are detected [3]. These statistics are baleful because cancer is a well-studied malignity, which has a slow progression, known risk factors and pre-neoplastic lesions that can be detected 
and treated [4]. Because the warning symptoms and signs are belated, colorectal neoplasm is found most often in the later stages, which drastically reduces the chances of applying radical curative treatment. Hence, the need is to introduce measures for colorectal cancer screening [5] and a better management of patients with this type of neoplasia. The aim of this study is to evaluate histological and immunohistochemical status of patients with metastatic colorectal cancer.

\section{Patients and Methods}

The statstical test included 166 colorectal cancer patients hospitalized in the Medical Oncologie Service in Oran University Hospital Center (CHUO), between January 2013 and Febrary 2016, aged between 25 and 80 years.

The data were recorded in clinical observation sheet of each patient.Clinical and laboratory data were entered into a Microsoft Excel database for statistical processing. With the program functions or averaged variables, confidence intervals, standard significance tests were performed comparing the data series. The statistical significance of the values was considered as $\mathrm{p}<0.05$.

For the histopathology study, there were surgically taken fragments of tumor tissue, which were fixed in $10 \%$ buffered formalin for 48 - 72 hours and processed for histological techniques including the classic paraffin. Paraffin-included samples were cut using the microtome in $4-\mu \mathrm{m}$ sections and then stained with Hematoxylin-Eosin. Immunohistochemical study aimed to label abnormal intestinal epithelium cells. For immunohistochemical study of paraffin-included material, we selected a total of 30 cases of colorectal adenocarcinomas. Since the histological sections were made of $3-\mu \mathrm{m}$ thickness, biological material was collected on slides superfrost ultra plus, after which they were kept in thermostat at $37^{\circ} \mathrm{C}$ for 24 hours to increase the adhesion of biological material. Following deparaffination and hydration of the histological sections, We pre-heat steamer or water bath with staining dish containing Sodium Citrate Buffer or Citrate Buffer until temperature reaches $95^{\circ} \mathrm{C}-100^{\circ} \mathrm{C}$, immerse slides in the staining dish. Place the lid loosely on the staining dish and incubate for 20 - 40 minutes (optimal incubation time should be determined by user). Washed in tap water before being cooked in citrate $\mathrm{pH} 6$ solution for 20 minutes to expose the antigen. After boiling, the solution was washed using phosphate-buffered saline (PBS).The sections were incubated with primary antibodies overnight, at $4^{\circ} \mathrm{C}$, and the next day the signal was amplified for 30 minutes using the secondary antibody immpact DAB peroxidase substrate (EnVision, Dako). The signal was detected with 3,3'-Diaminobenzidine (DAB, Dako). For immunohistochemical study, we used the antibodies found in Table 1 below.

Table 1. Antibodies used in the study.

\begin{tabular}{cccccc}
\hline Antibody & Producer & Clone & Clonality & Unmasking & Dilution \\
\hline Cytokeratin7 & Dako & OV-TL 12/30 & Ms Monoclonal & Sodium citrate, pH 6 & $1: 200$ \\
Cytokeratin20 & Dako & Ks20.8 & Ms Monoclonal & Sodium citrate, pH 6 & $1: 200$ \\
\hline
\end{tabular}

Ms-mouse. 


\section{Results}

In our series, the risck of most of types of malignancies in colorectal cancer increases by age. The youngest patient in the group was 23 years (diagnosed withrectal villous tumor), and the oldest was 81 years (diagnosed with lower rectal adénocarcinoma) (Figure 1 \& Figure 2).

Concerning the evolutionary stage of studied colorectal cancers, clinical, laboratory and intraoperative data allowed us to note that out of the 166 tumors, $12(7.41 \%)$ have been diagnosed in stage I, $47(28.14 \%)$ in stage II to stage III, 53 (31.85\%), and 54 $(32.6 \%)$ in stage IV (Table 2 ).

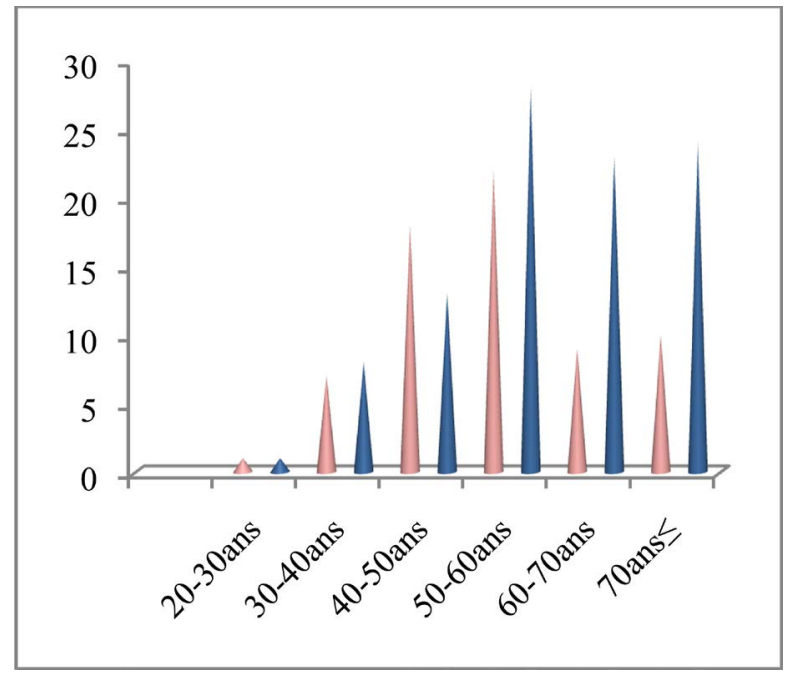

Figure 1. Distribution of patients by age.

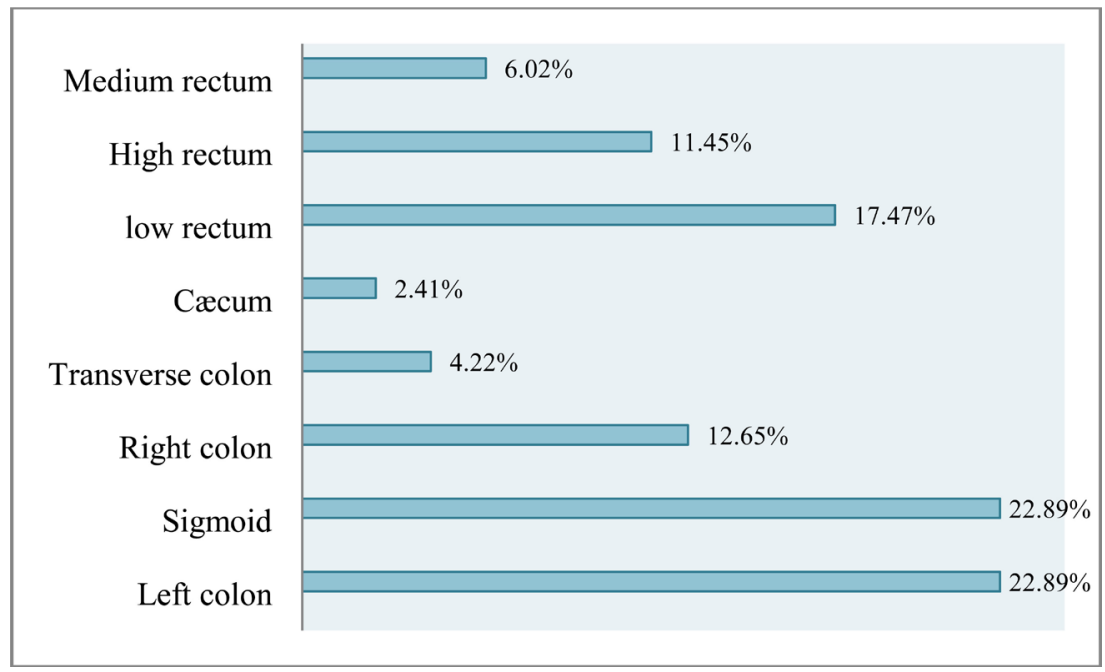

Figure 2. Topographic distribution of the studied group.

Table 2. Evolutionarystage of the colorectal adenocarcinome studied group.

\begin{tabular}{ccccc}
\hline Stages & I & II & III & IV \\
\hline Patient Number & 12 & 47 & 53 & 54 \\
$(\%)$ & 7.41 & 28.14 & 31.85 & 32.6 \\
\hline
\end{tabular}


Histopathological study showed that out of 166 cases of colorectal cancer, 166 (100\%) cases were adenocarcinomas. Regarding the adenocarcinomas, $143(86.4 \%)$ cases were Lieberkuhnian adenocarcinomas, 20 (12.24\%) cases were diagnosed as mucinous adenocarcinomas and $3(1.36 \%)$ patients were represented by the "signet ring cell" carcinomas. Regarding the degree of cell differentiation, out of the 143 adenocarcinomas, a number of $110(66.43 \%)$ were well-differentiated adenocarcinomas, 28 (16.43\%) were moderately differentiated, and $5(2.86 \%)$ cases were poorly differentiated adenocarcinomas.

For histopathological and immunohistochemical study we have choose 30 specimens from the archives of the Privat Laboratory (A. KORSO) of Pathology of pure adenocarcinomas of the colon processed to paraffin from as many patients, that were operated in the General Surgery (CHU and EHU). we selected cases of pure adenocarcinoma because they represented more than $3 / 4$ of operated colorectal tumors. Histopathological and immunohistochemical aspects varied greatly from one tumor to another. In all tumor types, concerning of the degree of differentiation we have observed many mitoses, including atypical mitotic figures.

The well-differentiated adenocarcinomas were all shown to contain immature mucous cell in varying proportions and cells with abundant microvilli (Figure 3(a) and Figure 3(b)). In moderately differentiated adenocarcinoma, we observed unequivocal intracytoplasmic mucin vacuoles, cellular and nuclear atypia were more numerous (Figure 4). The most extensive cellular changes occurred in poorly differentiated adenocarcinomas, generally composed of sheets of undifferentiated cells (Figure 5).

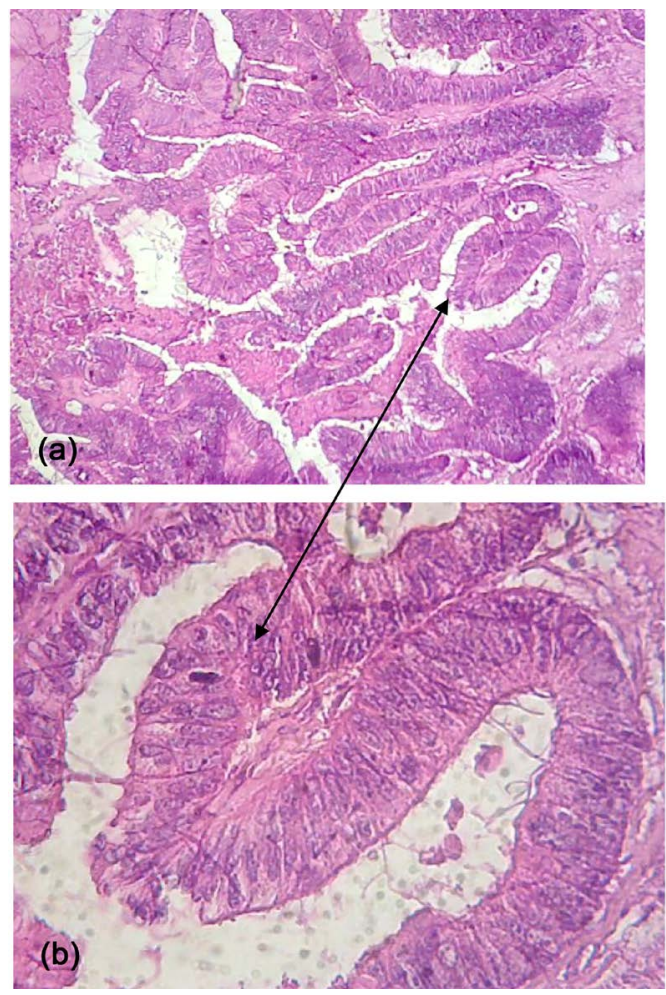

Figure 3. (a) Colon adenocarcinoma infiltrating in the mucous tunic. Hematoxylin-Eosin staining, 10x; (b) Well-differentiated adenocarcinoma with polymorphic epithelium, partially pseudostratified, which delineates large, irregular lumen glands filled with tumor, inflammatory or partially degraded cells. Hematoxylin-Eosin staining, 40×. 


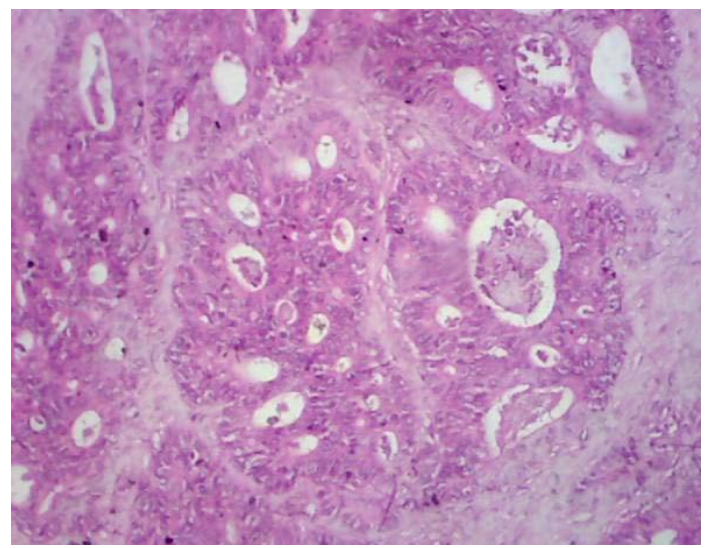

Figure 4. Image of moderately differentiated colon adenocarcinoma. Hematoxylin-Eosin staining, 10x.

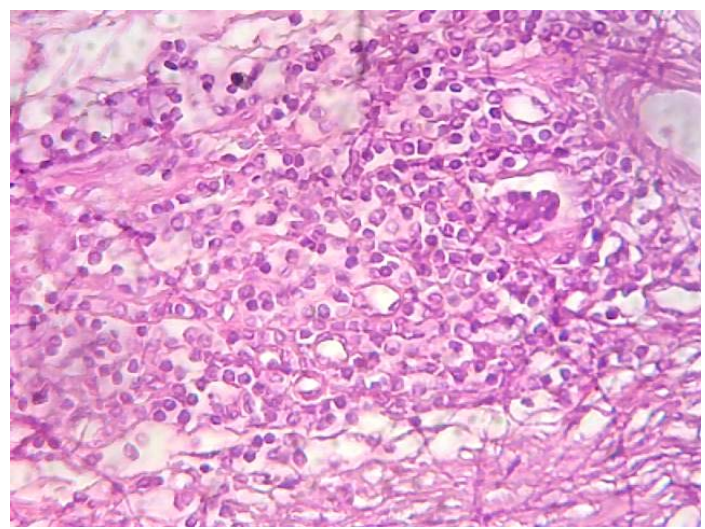

Figure 5. Image of poorly differentiated adenocarcinoma associated with moderate inflammatory reaction, $40 \times$.

Interpretation of immunohistochemical reactions focused primarily over highlighting the chromogen on the antigenic targets and the number of positive tumor cells. Thus, if no cell has been immunohistochemically labeled, we considered an absent reaction; if the reaction was positive in less than $10 \%$ of examined cells with a microscope objective of $20 \times$, we considered a poor response; if they were positive in $10 \%$ to $25 \%$ of the cells, we considered a moderate reaction reaction, and if it was positive in more than $25 \%$, we have found that the reaction was intense.

Several panels of immunohistochemical markers have been developed to allow for recognition of patterns suggestive of specific tumor types. One such immunohistochemical phenotype charachterized by markers commonly seen in colon cancer is inceasingly being recognized as a distinct favorable subset of cancer of unknown primary (CUP). We investigated the expressions of CK7 and CK20 in 30 cases of colorectal carcinoma [6] (Figures 6-10).

\section{Discussion}

The colorectal cancer deaths rates have dropped significantly in the past couple of decades. The death rate (the number of deaths per 100,000 people per year) of colorectal cancer isdecreasing,presumably through increased colorectal cancer screening [7]. In UK 
theincidence by age stratification is 4 cases/100,000 for people under the age of 50, 100 cases/100,000 for those aged $50-69$ and 300 cases/100,000 for those over the age of 70, same result are obtained in our study where the incidence rate of CRC has increased solely in people over 50 years, something [8], overall it growth dramatically after 40 years in patients in urban areas and those in rural areas [9]. which suggests that colorectal cancer typically results from a complex interaction between genetic and environmental influences.
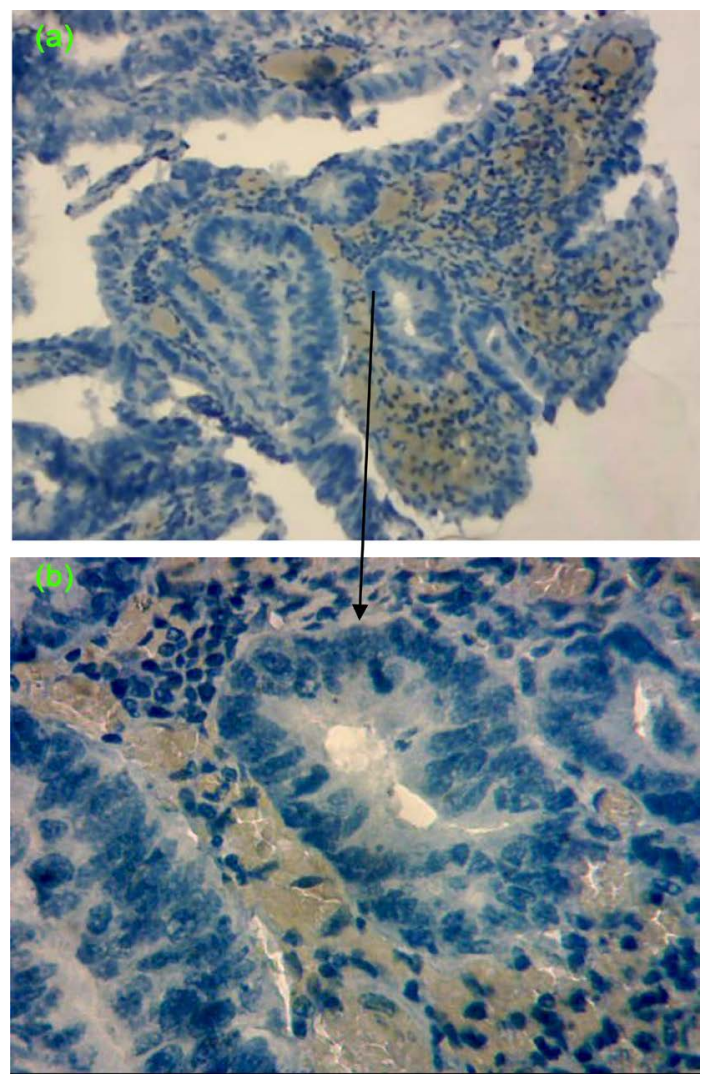

Figure 6. Well-differentiated adenocarcinoma with intense reaction to CK20. Anti-CK20 antibody immunostaining (a) 10×, (b) 40×.

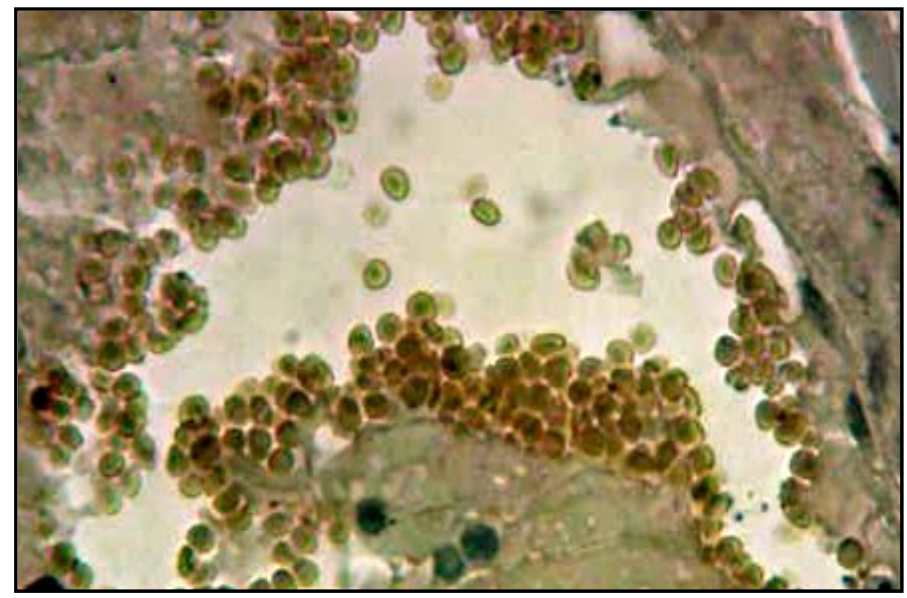

Figure 7. Poorly differentiated adenocarcinoma with moderate reaction to CK20. Anti-CK20 antibody immunostaining, 40×. 


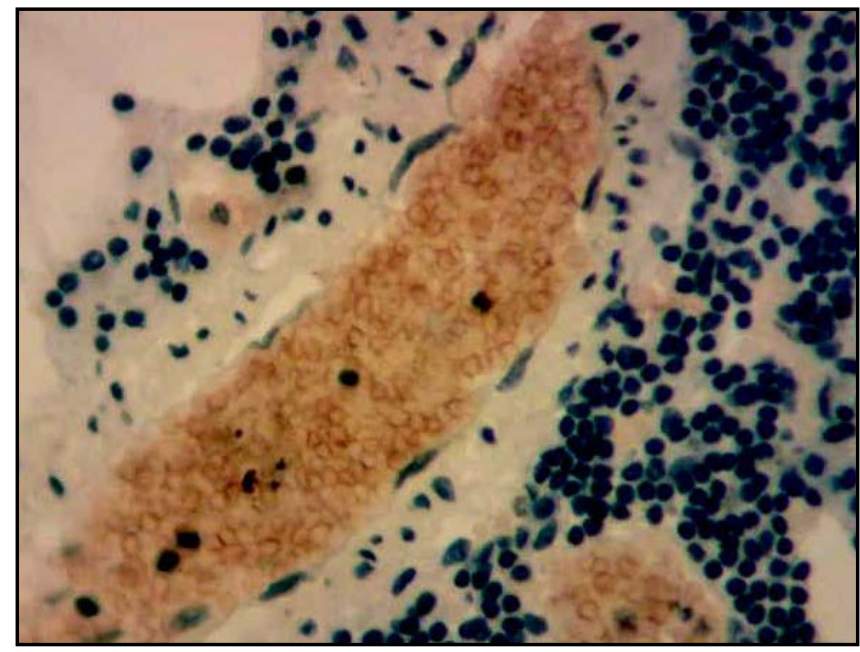

Figure 8. Mucinous adenocarcinoma with moderate reaction to CK20. Anti-CK20 antibody immunostaining, 40x.

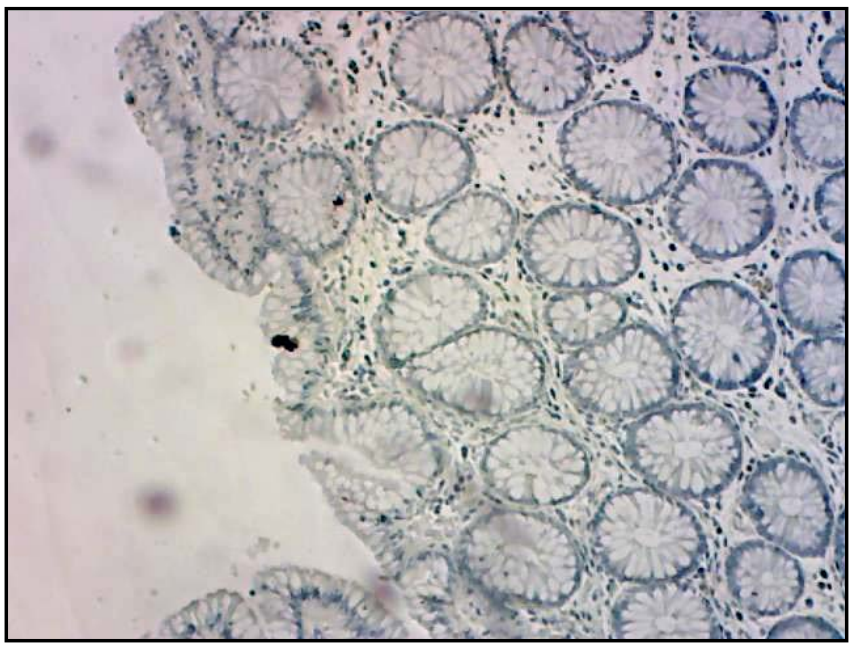

Figure 9. Normalcolonic mucosa showed negative staining to CK7. AntiCK7 immunostaining 100x.

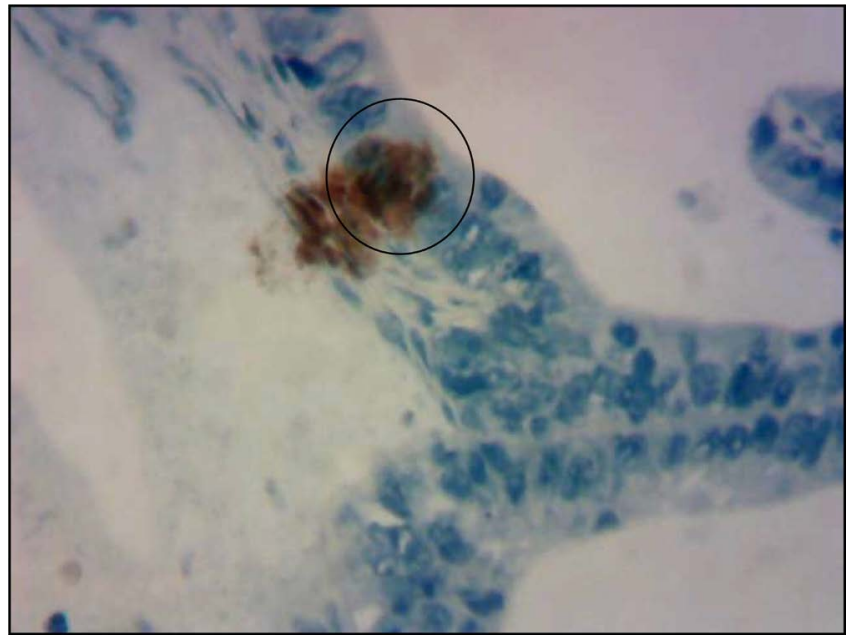

Figure 10. Well-differentiated adenocarcinoma with Weak reaction to CK7. Anti-CK7 antibody immunostaining 40×. 
Investigations have shown that DNA damage and somatic mutations occur during cancer progression in humans. [10]. In humans mucus production and composition changes with age [11]. All these data highlights the complex nature of malignant degeneration in the colon and the importance of age as a risk factor in the development of this cancer.

The difference in sex of patients with colorectal cancer, was not statistically significant. Of 166 patients with colorectal cancer, 68 (41\%) were females and 98 (59\%) males, According to some scientists the difference of incidence of such disease has to do with gender [12] [13] [14] [15].

In our study, tumor localization was predominant in the colon if we compare it with the segments of rectum. Two-third of colorectal cancer occur in the left colon and onethird in right colon, although women more often develop right-sided tumors. About of $20 \%$ of colorectal cancers develop in the rectum [16].

Regarding the tumor stage, we found that over $60 \%$ of patient in our series were diagnosed with stage III and IV tumors. $21 \%$ of colorectal cancers are diagnosed late, but behind time diagnosis is more common among some sociodemographic groups than others.It is distinctly clear that people living in areas with high proportion of poverty and unemployment have their colorectal cancer diagnosed at a late stage by comparing them with those living in other areas. Other authors have reported similar dataIn a study in Tunisia,analyzing a number of 280 colorectal cancers diagnosed, found that $25 \%$ were found to have stage I/II disease, $52.5 \%$ stage III and $22.5 \%$ with stage IV cancer [17].

Tumor grade refers to themicroscopic appearence of a malignancy of a predetermined class and histologic type and the mesure to wich it resembles the tissue of origin. In our series, more than halfof the tumors were classified as well-differentiated adenocarcinoma.

By against to some authors, moderately differentiated adenocarcinoma of the colon and rectum cancers can reach up to $70 \%$ [18].

The identification of the metastatic carcinoma of unrevealedsource can be very difficult. The determination of the primary site of the metastasis is a challenge to one and the other oncologists and pathologists, having conceivably important clinical and therapeutic consequences [19] [20]. Analysis of the expression pattern of CK7 and CK20 can give the clinician a suggestion of the origin of the tumor [11] [21].

Differential cytokeratin expression may be of use with intestinal tumours showing a different profile (Cytokeratin 20 positive/7 negative).

Normal epithelium of the small bowel, appendix and colorectum, and adenocarcinomas from these sites, are almost consistently CK7-/CK20+, helping to distinguish these adenocarcinomas from adenocarcinomas of many other primary sites [22] [23].

The CK7-/CK20+ pattern was identified in $65 \%$ to $95 \%$ of the colorectal adenocarcinomas in different series [9] [24] [25] [26] [27]. The CK7-/CK20+ immunopheno type was expressed by 20 (66.66\%) colorectal tumors, CK7+/CK20- 7 (23.33\%)and CK7+/CK20+ 3 $(10 \%)$ in the present study. Therefore by colonic epithelial tumors. Interestingly, several reports have described CK7 expression in colorectal adenocarcinoma, with expression ranging from 5\% to $74 \%$ [9] [24] [25] [26] [27].

CK20 reactivity was diffuse (more than $50 \%$ of cells were positive) in our cases and in 
the majority of colorectal carcinoma cases and mainly focal ( $<50 \%$ ofcells were positive) in gastric and pancreatic adenocarcinomas as in previous studies [25] [26] [27] [28].

\section{Conclusion}

In conclusion, colorectal cancer is affecting together women and men in relatively equal proportions. Most cancers were recorded in the left colon. More than half of the patients were staged III and IV at first admission. The histopathological study showed that about $100 \%$ of colorectal neoplasms were adenocarcinomas, frequently with well differentiation. Immunohistochemistry for CK7 and CK 20 help differentiate primary colorectal adénocarcinoma from metastasis. In our study, we found that more than $20 \%$ of patients with ck20+/ck7- phenotype had hepatic metastasis.

\section{References}

[1] Ferlay, J., Soerjomataram, I., Ervik, M., Dikshit, R., Eser, S., Mathers, C., Rebelo, M., Parkin, D.M., Forman, D. and Bray, F. (2014) GLOBOCAN 2012 v1.1, Cancer Incidence and Mortality Worldwide: IARC CancerBase No. 11 [Internet]. International Agency for Research on Cancer, Lyon. http://globocan.iarc.fr

[2] Sedkaoui, C. (2015) Chemotherapy and Targeted Therapy in Metastatic Colorectal Cancer. Doctoral Thesis.

[3] Kanthan, R., Senger, J.L. and Kanthan, S.C. (2012) Molecular Events in Primary and Metastatic Colorectal Carcinoma: A Review. Pathology Research International, 2012, Article ID: 597497.

[4] Worthley, D.L. and Leggett, B.A. (2010) Colorectal Cancer: Molecular Features and Clinical Opportunities. The Clinical Biochemist Reviews, 31, 31-38.

[5] Tinmouth, J., Baxter, N.N., Paszat, L.F., Rabeneck, L., Sutradhar, R. and Yun, L. (2014) Using Physician-Linked Mailed Invitations in an Organised Colorectal Cancer Screening Programme: Effectiveness and Factors Associated with Response. BMJ Open, 4, e004494. https://doi.org/10.1136/bmjopen-2013-004494

[6] Fleming, M., Ravula, S., Tatishchev, S.F. and Wang, H.L. (2012) Colorectal Carcinoma: Pathologic Aspects. Journal of Gastrointestinal Oncology, 3, 153-173.

[7] American Cancer Society (2016) Cancer Facts \& Figures 2016. American Cancer Society, Atlanta.

[8] GLOBOCAN (2000) Cancer Incidence, Mortality and Prevalence Worldwide. International Adgency for Research on Cancer European Network of Cancer Registers (IARC CancerBase No. 5).

[9] Bayrak, R., Yenidünya, S. and Haltas, H. (2011) Cytokeratin 7 and Cytokeratin 20 Expression in Colorectal Adenocarcinomas. Pathology Research and Practice, 207, 156-160. https://doi.org/10.1016/j.prp.2010.12.005

[10] Roncucci, L., Ponz de Leon, M., Scalmati, A., Malagoli, G., Pratissoli, S., Perini, M. and Chahin, N.J. (1988) The Influence of Age on Colonic Epithelial Cell Proliferation. Cancer, 62, 2373-2377. https://doi.org/10.1002/1097-0142(19881201)62:11<2373::AID-CNCR2820621120>3.0.CO; $2-\mathrm{Y}$

[11] Park, S.Y., Kim, B.H., Kim, J.H., Lee, S. and Kang, G.H. (2007) Panels of Immunohistochemical Markers Help Determine Primary Sites of Metastatic Adenocarcinoma. Archives of Pathology \& Laboratory Medicine, 131, 1561-1567.

[12] Center, M.M., Jemal, A. and Ward, E. (2009) International Trends in Colorectal Cancer 
Incidence Rates. Cancer Epidemiology, Biomarkers \& Prevention, 18, 1688-1694. https://doi.org/10.1158/1055-9965.EPI-09-0090

[13] Shah, S.A., Neoh, H.M., Rahim, S.S., Azhar, Z.I., Hassan, M.R., Safian, N. and Jamal, R. (2004) Spatial Analysis of Colorectal Cancer Cases in Kuala Lumpur. Asian Pacific Journal of Cancer Prevention, 15, 1149-1154.

[14] Payne, S. (2007) Not An Equal Opportunity Disease-A Sex and Gender-Based Review of Colorectal Cancer in Men and Women: Part I. The Journal of Men's Health \& Gender, 4, 131-139. https://doi.org/10.1016/j.jmhg.2007.03.005

[15] Deng, W., Long, L., Li, J.L., Zheng, D., Yu, J.H., Zhang, C.Y., Li, K.Z., Liu, H.Z. and Huang, T.R. (2014) Mortality of Major Cancers in Guangxi, China: Sex, Age and Geographical Differences from 1971 and 2005. Asian Pacific Journal of Cancer Prevention, 15, 1567-1574. https://doi.org/10.7314/APJCP.2014.15.4.1567

[16] Holt, P.R., Kozuch, P. and Mewar, S. (2009) Colon Cancer and the Elderly: From Screening to Treatment in Management of GI Disease in the Elderly. Best Practice \& Research Clinical Gastroenterology, 23, 889-907. https://doi.org/10.1016/j.bpg.2009.10.010

[17] Bouassida, M., Bilel, F., Bassem, M., Mohamed, F.C., Selim, S., Fathi, C., Souheil, B., Mohamed, M.M., Hassen, T., Mohamed, M.A. and Sadok, S. (2012) Histopathologic Characteristics and Short-Term Outcomes of Colorectal Cancer in Young Tunisian Patients: One Center's Experience. The Pan African Medical Journal, 12, 10.

[18] Duval, J.V., Savas, L. and Banner, B.F. (2000) Expression of Cytokeratins 7 and 20 in Carcinomas of the Extrahepatic Biliary Tract, Pancreas, and Gallbladder. Archives of Pathology \& Laboratory Medicine, 124, 1196-1200.

[19] Varadhachary, G.R. (2007) Carcinoma of Unknown Primary Origin. Gastrointestinal Cancer Research, 1, 229-235.

[20] Pavlidis, N., Briasoulis, E., Hainsworth, J. and Greco, F.A. (2003) Diagnostic and Therapeutic Management of Cancer of an Unknown Primary. European Journal of Cancer, 39, 1990-2005. https://doi.org/10.1016/S0959-8049(03)00547-1

[21] Pecciarini, L., Cangi, M.G. and Doglioni, C. (2001) Identifying the Primary Sites of Metastatic Carcinoma: The Increasing Role of Immunohistochemistry. Current Diagnostic Pathology, 7, 168-175. https://doi.org/10.1054/cdip.2001.0079

[22] Ramaekers, C., Van Niekerk, C., Poels, L., Schaafsma, E., Huijsmans, A., Robben, H., Schaart, G. and Vooijs, P. (1990) Use of Monoclonal Antibodies to Keratin7 in Differential Diagnosis of Adenocarcinomas. American Journal of Pathology, 136, 641-655.

[23] Tot, T. (1999) Adenocarcinomas Metastatic to the Liver. The Value of Cytokeratins 20 and 7 in the Search for Unknown Primary Tumors. Cancer, 85, 171-177. https://doi.org/10.1002/(SICI)1097-0142(19990101)85:1<171::AID-CNCR24>3.0.CO;2-V

[24] Wang, N.P., Zee, S., Zarbo, R.J., Bacchi, C.E. and Gown, A.M. (1995) Coordinate Expression of Cytokeratins 7 and 20 Defines Unique Subsets of Carcinomas. Applied Immunohistochemistry \& Molecular Morphology, 3, 99-107.

[25] Chu, P., Wu, E. and Weiss, L.M. (2000) Cytokeratin 7 and Cytokeratin 20 Expression in Epithelial Neoplasms: A Survey of 435 Cases. Modern Pathology, 13, 962-972. https://doi.org/10.1038/modpathol.3880175

[26] Park, S.Y., Kim, H.S., Hong, E.K. and Kim, W.H. (2002) Expression of Cytokeratins 7 and 20 in Primary Carcinomas of the Stomach and Colorectum and Their Value in the Differential Diagnosis of Metastatic Carcinomas to the Ovary. Human Pathology, 33, 10781085. https://doi.org/10.1053/hupa.2002.129422

[27] Saad, R.S., Silverman, J.F., Khalifa, M.A. and Rowsell, C. (2009) CDX2, Cytokeratins 7 and 20 Immunoreactivity in Rectal Adenocarcinoma. Applied Immunohistochemistry \& Mole- 
cular Morphology, 17, 196-201. https://doi.org/10.1097/PAI.0b013e31819268f2

[28] Zhang, P.J., Shah, M., Spiegel, G.W. and Brooks, J.J. (2003) Cytokeratin 7 Immunoreactivity in Rectal Adenocarcinomas. Applied Immunohistochemistry \& Molecular Morphology, 11, 306-310. https://doi.org/10.1097/00129039-200312000-00005

Submit or recommend next manuscript to SCIRP and we will provide best service for you:

Accepting pre-submission inquiries through Email, Facebook, LinkedIn, Twitter, etc. A wide selection of journals (inclusive of 9 subjects, more than 200 journals) Providing 24-hour high-quality service User-friendly online submission system Fair and swift peer-review system Efficient typesetting and proofreading procedure Display of the result of downloads and visits, as well as the number of cited articles Maximum dissemination of your research work

Submit your manuscript at: http://papersubmission.scirp.org/ Or contact jct@scirp.org 